\title{
Forecasting Quarterly Russian GDP Growth with Mixed-Frequency Data
}

\author{
Heiner Mikosch, KOF Swiss Economic Institute, ETH Zurich \\ mikosch@kof.ethz.ch \\ Laura Solanko, Bank of Finland Institute for Economies in Transition (BOFIT) \\ laura.solanko@bof.i
}

This paper presents a pseudo real-time out-of-sample forecast exercise for short-term forecasting and nowcasting quarterly Russian GDP growth with mixed-frequency data. We employ a large set of indicators and study their predictive power for different subperiods within the forecast evaluation period 2008-2016. Four indicators consistently figure in the list of top-performing indicators: the Rosstat key sector economic output index, the OECD composite leading indicator for Russia, household banking deposits, and money supply M2. Aside from these indicators, the top indicators in the 2008-2011 evaluation period are traditional real-sector variables, while those in the 2012-2016 evaluation period largely comprise monetary, banking sector and financial market variables. We also compare the forecast accuracy of three different mixed-frequency forecasting model classes (bridge equations, MIDAS models, and U-MIDAS models). Differences between the performance of model classes are generally small, but for the 2008-2011 period MIDAS models and U-MIDAS models outperform bridge equation models.

Keywords: forecasting, Russia, GDP growth, mixed frequency data, MIDAS, bridge equations

JEL Codes: C53, E27

\author{
Citation: Mikosch, $\mathrm{H}$. \\ and Solanko, L. (2019). Forecasting \\ Quarterly Russian GDP Growth \\ with Mixed-Frequency Data. \\ Russian Journal of Money \\ and Finance, 78(1), pp. 19-35.
}

doi: $10.31477 /$ rjmf.201901.19

\section{Introduction}

Official GDP figures are typically available at a quarterly frequency and with a considerable publication lag, whereas many other economic indicators, such as industrial production, are available at higher frequencies and with short publication lags. Mixed-frequency forecasting models employ the higherfrequency indicators to forecast or nowcast quarterly GDP growth in order to 
inform policymakers about the future or current state of the economy. This paper presents a pseudo real-time out-of-sample forecast and nowcast exercise for quarterly Russian GDP growth over the subsample period 2008-2016 using a large set of monthly and daily indicators, several mixed-frequency forecasting models, and forecast pooling techniques.

There currently exists a large body of forecasting studies with data from various countries. Surprisingly, however, the literature contains only a few forecasting studies for Russian GDP growth, even though Russia is a major emerging economy and currently the sixth biggest economy in the world (in terms of total GDP based on PPP exchange rates). Rautava (2013) employs a structural vector error-correction macro model built for forecasting purposes and finds that the sharp contraction in Russian output in 2009 can be explained by oil prices and excess uncertainty. Porshakov et al. (2016) use a dynamic factor model and a set of 116 indicators to short-term forecast and nowcast quarterly Russian GDP for the period 2012-2014. They find that the model generally outperforms simple benchmark models in terms of predictive accuracy and that new statistical releases of monthly indicators tend to consistently improve predictive accuracy, at least for the nowcast horizon. Dahlhaus et al. (2017) employ a DFM and nowcast GDP in the BRIC countries and Mexico, using 14 monthly macroeconomic indicators in the case of Russia. Blinov (2017) demonstrates the predictive power of real money supply for forecasting Russian GDP growth.

This paper contributes to the still scarce research on forecasting Russian GDP growth. For this purpose, we employ three established mixed-frequency forecasting model classes (bridge, mixed data sampling (MIDAS), and unrestricted MIDAS (U-MIDAS)), a large set of different model specifications within the aforementioned model classes, a large set of monthly indicators (247), six different forecast and nowcast horizons, and a long evaluation period (2008Q1-2016Q4). The main aim of the paper is to ascertain which indicators have been most valuable for nowcasting and forecasting Russian GDP growth in recent years.

We identify a fairly large number of monthly indicators that significantly improve upon simple benchmark forecasting models in most evaluation periods. If nothing else, our results flag a number of indicators Russia-watchers might want to consider in forecasting and nowcasting Russian GDP growth.

As recent nowcasting literature suggests considerable differences between European countries in terms of predictability of GDP growth during and after the Great Recession (see e.g. Schumacher, 2016), we split our evaluation sample into two subsamples. The high-volatility period of 2008Q1-2011Q4 covers the Great Recession and the subsequent recovery. The downward trend period of 2012Q12016Q4 brackets the transition to lower growth rates and the 2015 recession. We find that GDP growth was more difficult to predict across all indicators during the 2008-2011 period than during the 2012-2016 period relative to simple 
benchmark forecasts. Nevertheless, we identify certain indicators with high predictive power during the 2008-2011 period.

A small number of indicators consistently figures among the top-performing indicators for all the forecast and nowcast horizons studied, and for both forecast evaluation periods: the monthly key sectors economic output index (published by Rosstat), the monthly composite leading indicator for Russia (published by the OECD), and two indicators published by the Central Bank of Russia (CBR) household banking deposits in Russian roubles and money supply M2. Aside from these four indicators, the best-performing indicators are distinctly different in each period. The best indicators in the 2008-2011 period include traditional real-sector variables, while in the 2012-2016 period the best indicators are mostly monetary, banking sector, and financial market variables.

We also find that differences in the forecast performance of our three models are generally marginal. During the Great Recession, however, the U-MIDAS models and MIDAS models do considerably better than the bridge models. Taken together, these findings support the view that the precursors for growth in the Russian economy have changed since the Great Recession.

The next section provides a comparison between the three forecasting model classes. Section 3 describes the data used in the empirical forecast exercise. Section 4 outlines the design of the forecast exercise. Section 5 presents the empirical findings, and Section 6 concludes.

\section{Mixed frequency forecasting models}

The paper considers three different model classes for forecasting with mixedfrequency data: bridge equations, MIDAS models and U-MIDAS models. ${ }^{1}$

Bridge equations are popular in policy institutions because they are easy to implement and transparent. Applications in the literature include Ingenito and Trehan (1996), Baffigi et al. (2004), Golinelli and Parigi (2007), Diron (2008), Hahn and Skudelny (2008), Rünstler et al. (2009), Bulligan et al. (2010), Angelini et al. (2011), Camacho et al. (2013), Foroni and Marcellino (2014), Schumacher (2016) and Bulligan et al. (2015). This paper employs the classical bridge equations procedure as outlined in e.g. Schumacher (2016). To briefly explain the three-step procedure: first, a high-frequency (monthly) indicator is forecast using an iterated autoregressive (AR) model. Next, the high-frequency indicator is aggregated to a lower (quarterly) frequency. Following e.g. Chow and Lin (1971), the form of the time-aggregation function is determined by the stock or flow nature of the indicator and whether it comes in levels or growth rates. For instance, if the indicator is a (stationary) flow variable, such as exports, the quarterly variable observation

\footnotetext{
${ }^{1}$ See Foroni and Marcellino (2013) for a survey on econometric methods for forecasting with mixedfrequency data.
} 
is the sum of the three-monthly variable observations in this particular quarter. If the indicator is a stock variable, such as money supply, the quarterly variable observation is simply equal to the third monthly observation in the quarter. In a final step, quarterly GDP growth is forecasted using the time-aggregated indicator and lagged GDP growth. As an alternative, quarterly GDP growth is forecasted using the time-aggregated indicator only, omitting lagged values of GDP growth.

MIDAS was developed by Ghysels and co-authors (e.g. Ghysels et al., 2007; Andreou et al., 2010; Andreou et al., 2011). Applications include Clements and Galvão (2008, 2009), Armesto et al. (2010), Kuzin et al. (2013), Drechsel and Scheufele (2012), Andreou et al. (2013), Duarte (2014) and Ferrara et al. (2014). A low-frequency variable is forecasted using a potentially large number of (lagged) observations of a high-frequency indicator where the lag coefficients are modelled as a potentially very flexible non-linear distributed lag function. To explain the MIDAS approach more formally: let $y_{t}^{Q}$ be quarterly GDP growth of quarter $t=1, \ldots, T$ and let $x_{t-2 / 3}^{M}, x_{t-1 / 3}^{M}$ and $x_{t}^{M}$ be the first monthly observation, the second monthly observation and the third monthly observation of an indicator (e.g. growth in money supply) within quarter $t$. The basic single-indicator MIDAS estimation equation is then written

$$
y_{t}^{Q}=\beta_{0}+\sum_{j=0}^{J} b(j ; \boldsymbol{\theta}) x_{t-h / 3-j / 3}^{M}+\varepsilon_{t},
$$

where $\beta_{0}$ is a constant parameter, $\varepsilon_{t}$ is an error term, $J$ denotes the potentially very large lag length and the forecast horizon is determined by $h$. For instance, suppose one wants to forecast $y_{t}^{Q}$ at the last day of quarter $t$, where both $y_{t}^{Q}$ and $x_{t}^{M}$ are not yet published. In this case, $h=1$. Suppose instead one wants to forecast $y_{t}^{Q}$ at the last day of the second month in quarter $t$, where $x_{t-1 / 3}^{M}$ is not yet published. In this case, $h=2$, and so on. $b(j ; \boldsymbol{\theta})$ is a distributed lag function that depends on the lag index $j$ and on a small number of parameters $\theta_{0}, \ldots, \theta_{p}$, summarised in the parameter vector $\boldsymbol{\theta}$. One or several lagged values of GDP growth may be included on the right-hand side of the MIDAS estimation equation, in which case the model is called autoregressive MIDAS. This paper implements the basic single-indicator MIDAS model and the autoregressive single-indicator MIDAS model as described in Clements and Galvão (2009), with one important difference. Instead of using the exponential Almon lag polynomial, we employ the non-exponential Almon lag polynomial originally proposed by Almon (1965):

$$
b(j ; \boldsymbol{\theta})=\sum_{p=0}^{P} \theta_{p} j^{p},
$$

where $P$ denotes the order of the polynomial. In the empirical application, polynomials of order 1, 2, 3 and 4 are employed. The reason for this choice is that, in our preliminary analysis as well as in previous research (Mikosch and Zhang, 2014), the use of the non-exponential Almon lag polynomial led to 
higher forecast accuracy than the use of the exponential Almon lag polynomial or alternative non-linear polynomial schemes. Notably, despite the fact that the non-exponential Almon lag polynomial is highly non-linear, MIDAS models with non-exponential Almon lag polynomials can be transformed into linear form. Ordinary least squares (OLS) estimation of the model parameters $\beta_{0}, \theta_{0}, \ldots, \theta_{p}$ thereby becomes feasible. ${ }^{2}$ MIDAS attempts to balance two goals which are usually traded off against each other. The first goal is model flexibility, i.e. allowing the relative importance of any lagged observation compared to any other lagged observation to be determined by the data and not pre-determined by the model itself. The second goal is a parsimoniously parameterised model that prevents parameter proliferation or overfitting.

Foroni et al. (2015) propose unrestricted mixed-frequency regressions and call the approach unrestricted MIDAS (U-MIDAS). Here, a low-frequency variable is forecasted with (lagged) observations of a high-frequency indicator, where the lag coefficients are left fully unrestricted and hence can be estimated by OLS. While extremely flexible, the U-MIDAS model is not parsimonious when the number of indicator lags is large. Thus, the advantages of U-MIDAS are only superior to alternative weighting schemes when the number of lags is sufficiently small (see the evaluation in Foroni et al., 2015). In this paper, we treat the U-MIDAS approach as a separate model class to compare its forecast performance with the performance of MIDAS and bridge equations. The basic and the autoregressive single-indicator U-MIDAS models are implemented as described in Foroni et al. (2015).

Following the literature cited above on forecasting with bridge, MIDAS, and U-MIDAS models, we refrain from using models with multiple predictor variables. Instead, we always include only one indicator at a time in a model, and then pool the forecasts stemming from all the individual-predictor models using a forecast combinations approach as described in Section 4.

\section{Data}

We forecast the year-on-year growth rate of Russian real GDP as published by the Russian Statistical Agency Rosstat. ${ }^{3}$ The GDP data is released at a quarterly frequency with a first estimate for the GDP of any quarter being released around the fifteenth day of the second month of the next quarter $t+1$. We use data from 1996Q1 onwards because the data from earlier years are not fully comparable.

\footnotetext{
${ }^{2}$ See e.g. Mikosch and Zhang (2014, Appendix 6.1). This feature distinguishes the non-exponential Almon lag polynomial from alternative non-linear polynomials which require non-linear least squares estimation.

${ }^{3}$ Rosstat has two consistent GDP series: SNA 2008 for the years 2012 to 2017 and the older SNA 1993, which covers the years 1996 to 2011 . We make what we believe is a realistic assumption that real growth rates of the headline GDP figure are consistent over the data.
} 
In collecting the indicators for forecasting quarterly GDP growth, we include all available data series and make no prior judgements as to the perceived economic significance of a particular indicator. Russian statistics have evolved considerably over the past decades, and many new data series are available from the early- or mid-2000s. To ensure a sufficiently long period for parametrisation of the forecasting models, we include only series that start in 2001 or earlier. The final dataset includes 247 macroeconomic and financial variables. Having a large dataset is essential when using a forecast pooling strategy, as we do in this paper (see Section 4). Forecast pooling is a way of finding an optimal aggregation over many indicators, each of which reflects only a small part of the economy. Most variables are at monthly frequency. Indicators that come at daily or weekly frequency are included in monthly averages following Porshakov et al. (2016). We employ most variables in levels (if stationary) and in year-on-year growth rates. Some variables are published in year-on-year growth rates or month- on-month growth rates only and hence are employed in growth rates only. A detailed list of the variables is displayed in the working paper version of this paper (see Mikosch and Solanko, 2017).

The release dates of the indicators are carefully tracked. This tracking allows us to deal with 'ragged edges' in the data (Wallis, 1986) and to ensure that only those indicator observations which were actually available at a particular forecast date/ forecast horizon are employed as an input. In this way, we run a pseudo real-time out-of-sample forecasting evaluation experiment (see Section 4).

\section{Design of the forecast exercise}

This paper evaluates the forecast performance of the aforementioned model classes and the aforementioned indicators for different forecast horizons. Specifically, GDP growth for each quarter is forecasted at the end of each month from six months before the end of $t$ (sixth monthly forecast horizon) up to and including the last month of $t$ (first monthly forecast horizon). The six forecast horizons allow us to track closely how forecast errors evolve as new data continue to be released over time. As quarterly Russian GDP growth is released around 1.5 months after the end of a quarter, the first monthly forecast horizon is still 1.5 months ahead of the GDP release for the quarter.

We conduct a pseudo real-time out-of-sample forecasting evaluation experiment with rolling estimation and forecasting following e.g. Kuzin et al. (2013). The out-of-sample forecast evaluation period is 2008Q1-2016Q4, which is split into two parts as described in the Introduction. The rolling re-estimation and forecast procedure is applied separately for all the six forecast horizons: with each forecast step, the estimation sample is shifted forward by one quarter, all models are re-estimated and the next forecast is generated. This procedure results, for each separate forecast horizon, in a series of forecasts and forecast errors. 
Following the literature on forecasting with bridge, MIDAS and U-MIDAS models, we run models which always include only one individual indicator at a time. Furthermore, for each of the model classes numerous different model specifications are employed which differ with regard to lag length, polynomial order, and/or autoregressive structure. The Appendix provides an overview of all model specifications. Each model specification generates a separate forecast. In turn, a two-step weighted averaging forecast combinations procedure based on the mean square forecast error performance of the past four quarters is applied as described in Kuzin et al. (2013), Stock and Watson (2004) and Timmermann (2006). First, forecasts stemming from all alternative specifications are pooled for each indicator, each model class and each forecast horizon separately. ${ }^{4}$ Second, the resulting pooled forecasts are pooled again in the same manner over all model classes in order to compare the forecast performance of single indicators against each other at the different forecast horizons (see Sections 5.1 and 5.2). As an alternative second step, the first-step pooled forecasts are pooled over all indicators in order to compare the forecast performance of the different model classes at the different forecast horizons (see Section 5.3).

\section{Empirical results}

\subsection{Top indicators}

As a first step in the empirical analysis, we identify the best-performing single indicators for forecasting Russian GDP growth in the two out-of-sample evaluation periods of 2008Q1-2011Q4 and 2012Q1-2016Q4 in terms of root mean squared forecast errors (RMSFEs). The RMSFEs for the indicators are calculated from the two-step pooled forecasts over all model specifications and all model classes as described in Section 4. Table 1 reports the RMSFEs of the top ten indicators

\footnotetext{
${ }^{4}$ To explain the weighted averaging forecast combinations procedure in more detail: each model class comes with various different specifications (see Appendix). We generate a forecast from each model specification inside a model class for a particular indicator, at a particular forecast date and for a particular forecast horizon. Next, we average, for a particular indicator, at a particular forecast date and for a particular forecast horizon, all forecasts stemming from the different model specifications by attaching to each forecast a weight between 0 and 1 , where all weights add up to one (weighted averaging). The weights are calculated as follows following Kuzin et al. (2013): for a particular indicator, at a particular forecast date and for a particular forecast horizon we calculate, for each model specification, the rolling mean square forecast error (MSFE) from the forecasts of the previous four quarters. Each MSFE is then divided by the sum of the MSFEs of all model specifications such that the MSFEs of all model specifications sum to one (normalisation). Finally, the combination weight for each model forecast is the inverse of the normalised MSFE divided by the sum of all normalised inverted MSFEs. To understand the procedure intuitively: instead of selecting forecast models based on in-sample criteria such as the Akaike information criterion or the Bayesian information criterion, we weight forecasts from different model specifications according to their forecast performance in the past four quarters (where we openly admit that four quarters is a somewhat arbitrary choice). The better a model specification has performed during this recent past, the higher its weight in the weighted averaging construction of the current pooled forecast.
} 
relative to the RMSFE of a benchmark model, the rolling window in-sample mean GDP growth. ${ }^{5}$ Values smaller than one indicate performance better than the benchmark. The rolling window in-sample mean benchmark has proved to be a strong competitor in earlier studies (e.g. Giannone et al., 2008). For the sake of robustness, the result tables also present comparisons with an alternative benchmark model class, the AR model. ${ }^{6}$ Although GDP growth is forecast at various monthly horizons as described in Section 4, we save space here by reporting only average RMSFEs for the nowcast horizon (= average RMSFEs over the first, second and third monthly horizon as described in Section 4) and average RMSFEs for the onequarter-ahead forecast horizon (= average RMSFEs over the fourth, fifth and sixth monthly horizons as described in Section 4$)^{7}{ }^{7}$

Table 1. Performance of the top ten monthly indicators for predicting quarterly Russian GDP growth

\begin{tabular}{|c|c|c|c|c|c|}
\hline \multicolumn{6}{|c|}{ Forecast period 2008-2011 } \\
\hline Nowcast horizon & $\begin{array}{l}\text { Relative } \\
\text { RMSFE }\end{array}$ & $p$-value & $\begin{array}{l}\text { One-quarter ahead } \\
\text { forecast horizon }\end{array}$ & $\begin{array}{l}\text { Relative } \\
\text { RMSFE }\end{array}$ & $p$-value \\
\hline $\begin{array}{l}\text { Rosstat key sectors } \\
\text { economic output } \\
\text { index, yoy }\end{array}$ & 0.35 & 0.02 & $\begin{array}{l}\text { OECD composite } \\
\text { leading indicator, yoy }\end{array}$ & 0.50 & 0.05 \\
\hline $\begin{array}{l}\text { Railway freight } \\
\text { turnover, yoy }\end{array}$ & 0.38 & 0.08 & Interbank loans, yoy & 0.61 & 0.04 \\
\hline $\begin{array}{l}\text { Producer price index } \\
\text { for construction } \\
\text { materials (cement), } \\
\text { yoy }\end{array}$ & 0.40 & 0.03 & $\begin{array}{l}\text { Producer price index } \\
\text { for construction } \\
\text { materials (cement), } \\
\text { yoy }\end{array}$ & 0.69 & 0.03 \\
\hline $\begin{array}{l}\text { Industrial production, } \\
\text { yoy }\end{array}$ & 0.41 & 0.06 & $\begin{array}{l}\text { Money supply M2, } \\
\text { yoy }\end{array}$ & 0.72 & 0.07 \\
\hline $\begin{array}{l}\text { OECD composite } \\
\text { leading indicator, } \\
\text { yoy }\end{array}$ & 0.42 & 0.07 & $\begin{array}{l}\text { Rosstat key sectors } \\
\text { economic output } \\
\text { index, yoy }\end{array}$ & 0.73 & 0.03 \\
\hline $\begin{array}{l}\text { Manufacturing } \\
\text { production, yoy }\end{array}$ & 0.46 & 0.11 & $\begin{array}{l}\text { Export price index } \\
\text { for mineral fertilizers, } \\
\text { yoy }\end{array}$ & 0.75 & 0.08 \\
\hline $\begin{array}{l}\text { Household banking } \\
\text { deposits, yoy }\end{array}$ & 0.47 & 0.13 & $\begin{array}{l}\text { Industrial production, } \\
\text { yoy }\end{array}$ & 0.77 & 0.12 \\
\hline $\begin{array}{l}\text { REB diffusion index: } \\
\text { Enterprises with } \\
\text { rising stocks over } \\
1 \text { month, yoy }\end{array}$ & 0.47 & 0.09 & $\begin{array}{l}\text { Household banking } \\
\text { deposits, yoy }\end{array}$ & 0.77 & 0.10 \\
\hline $\begin{array}{l}\text { Money supply M2, } \\
\text { yoy }\end{array}$ & 0.47 & 0.05 & $\begin{array}{l}\text { Household deposit } \\
\text { rate for demand } \\
\text { deposits in Russian } \\
\text { rubels, yoy }\end{array}$ & 0.79 & 0.18 \\
\hline
\end{tabular}

Table 1 continues on p. 27

\footnotetext{
${ }^{5}$ The RMSFE results for the other indicators are available on request.

${ }^{6}$ Numerous AR model specifications are employed, some iterative and some direct, differing with regard to lag length (see Appendix). The forecasts stemming from the alternative specifications are then pooled using weighted averaging based on past forecast errors, as described in Section 4.

7 The separate RMSFEs for the monthly horizons are available on request.
} 
Continuation, Table 1 begins on p. 26

\begin{tabular}{|c|c|c|c|c|c|}
\hline \multicolumn{6}{|c|}{ Forecast period 2008-2011 } \\
\hline Nowcast horizon & $\begin{array}{l}\text { Relative } \\
\text { RMSFE }\end{array}$ & $p$-value & $\begin{array}{l}\text { One-quarter ahead } \\
\text { forecast horizon }\end{array}$ & $\begin{array}{l}\text { Relative } \\
\text { RMSFE }\end{array}$ & $p$-value \\
\hline $\begin{array}{l}\text { Ferrous metals } \\
\text { railway freight } \\
\text { turnover in tonnes, } \\
\text { yoy }\end{array}$ & 0.48 & 0.21 & $\begin{array}{l}\text { Agricultural } \\
\text { production, yoy }\end{array}$ & 0.79 & 0.04 \\
\hline \multicolumn{6}{|c|}{ Forecast period 2012-2016 } \\
\hline Nowcast horizon & $\begin{array}{l}\text { Relative } \\
\text { RMSFE }\end{array}$ & $p$-value & $\begin{array}{l}\text { One-quarter ahead } \\
\text { forecast horizon }\end{array}$ & $\begin{array}{l}\text { Relative } \\
\text { RMSFE }\end{array}$ & $p$-value \\
\hline $\begin{array}{l}\text { Money supply M0 } \\
\text { (cash), yoy }\end{array}$ & 0.23 & 0.00 & $\begin{array}{l}\text { RTS stock market } \\
\text { index, yoy }\end{array}$ & 0.30 & 0.00 \\
\hline $\begin{array}{l}\text { Rosstat key sectors } \\
\text { economic output } \\
\text { index, yoy }\end{array}$ & 0.24 & 0.00 & $\begin{array}{l}\text { Money supply M0 } \\
\text { (cash), yoy }\end{array}$ & 0.33 & 0.00 \\
\hline $\begin{array}{l}\text { RTS stock market } \\
\text { index, yoy }\end{array}$ & 0.25 & 0.02 & $\begin{array}{l}\text { Household banking } \\
\text { deposists, yoy }\end{array}$ & 0.34 & 0.01 \\
\hline Monetary base, level & 0.27 & 0.01 & Monetary base, level & 0.36 & 0.00 \\
\hline $\begin{array}{l}\text { CBR foreign exchange } \\
\text { reserves, yoy }\end{array}$ & 0.29 & 0.05 & $\begin{array}{l}\text { Money supply M2, } \\
\text { yoy }\end{array}$ & 0.36 & 0.03 \\
\hline $\begin{array}{l}\text { Urals crude oil price } \\
\text { in USD per barrel, } \\
\text { yoy }\end{array}$ & 0.29 & 0.07 & $\begin{array}{l}\text { Number of } \\
\text { unemployed persons }\end{array}$ & 0.40 & 0.02 \\
\hline $\begin{array}{l}\text { Money supply M2, } \\
\text { yoy }\end{array}$ & 0.30 & 0.06 & $\begin{array}{l}\text { CBR foreign exchange } \\
\text { reserves, yoy }\end{array}$ & 0.41 & 0.05 \\
\hline $\begin{array}{l}\text { Household banking } \\
\text { deposists, yoy }\end{array}$ & 0.30 & 0.07 & $\begin{array}{l}\text { Baker-Bloom-Davis } \\
\text { economic policy } \\
\text { uncertainty index, } \\
\text { level }\end{array}$ & 0.42 & 0.07 \\
\hline $\begin{array}{l}\text { Baker-Bloom-Davis } \\
\text { economic policy } \\
\text { uncertainty index, } \\
\text { level }\end{array}$ & 0.31 & 0.10 & $\begin{array}{l}\text { OECD composite } \\
\text { leading indicator, yoy }\end{array}$ & 0.42 & 0.08 \\
\hline $\begin{array}{l}\text { OECD composite } \\
\text { leading indicator, yoy }\end{array}$ & 0.31 & 0.11 & $\begin{array}{l}\text { Rosstat key sectors } \\
\text { economic output } \\
\text { index, yoy }\end{array}$ & 0.46 & 0.02 \\
\hline
\end{tabular}

Note: the table reports RMSFEs from forecasts of quarterly Russian GDP growth by univariate-indicator models relative to the RMSFE from forecasts by a benchmark model, the rolling window in-sample mean GDP growth. The smaller the relative RMSFE, the bigger the improvement upon the benchmark. The RMSFEs of the nowcast horizon equal the average RMSFEs over the first, second and third monthly forecast horizons (see Section 4). The RMSFEs of the one-quarter-ahead horizon equal the average RMSFEs over the fourth, fifth and sixth monthly forecast horizons. Improvements in forecast performance of the indicators shown over forecasts from the benchmark model are always statistically significant at the 5\% level according to the Giacomini and White (2006) test of unconditional equal predictive ability. $p$-values refer to the Giacomini and White test, indicating whether improvements in forecast performance compared to forecasts from an alternative benchmark, the AR model class, are statistically significant. Abbreviations: yoy - year-on-year growth rate. CBR - Central Bank of the Russian Federation. REB - Russian Economic Barometer, compiled by the IMEMO Institute of the Russian Academy of Sciences. Rosstat - Federal State Statistics Service.

Many indicators easily beat our benchmark in forecasting quarterly GDP growth. For the nowcast horizon, a total of 206 variables in the forecast period 2008-2011 and 225 variables in the forecast period 2012-2016 have relative 
RMSFEs smaller than one. Second, the RMSFEs are clearly smaller in the latter forecast period, indicating that the single-indicator models have on average become better in nowcasting the Russian economy relative to the benchmark. This finding is not that surprising, given that the first period includes volatile times, e.g. a sudden drop in GDP in 2008Q4-2009Q4 and rapid recovery thereafter.

A small number of indicators consistently figure in the top ten for both horizons (nowcast and one-quarter-ahead) and both forecast periods (2008-2011 and 2012-2016): the monthly key sectors economic output index (published by Rosstat), the monthly composite leading indicator for Russia (published by the OECD) and two indicators published by the CBR, household banking deposits in Russian roubles and money supply M2. It is noteworthy that Rosstat and the OECD do a good job of tracking Russian GDP on a monthly basis, despite the fact that the OECD leading indicator is released with a lag of around one and a half months, hence substantially later than the other indicators.

Aside from the aforementioned four indicators, the set of best-performing variables differs markedly between the two forecast periods. In 2008-2011, the best indicators include very traditional real sector variables as well as price and survey variables related to real sector production: industrial production, agricultural production, railway freight turnover, ferrous metals freight turnover, the producer price index for construction materials and the export price index for mineral fertilisers. None of these indicators makes it into the set of bestperforming indicators for the 2012-2016 period. Here, the best indicators include mostly monetary, banking sector and financial market variables: money supply M0, the monetary base, foreign exchange reserves, the monthly average of the daily RTS stock market index, and the economic policy uncertainty index for Russia published by Baker, Bloom and Davis (2015).

The difference in the set of best-performing indicators between the two forecast periods suggests that the factors supporting GDP growth in the volatile period of the Great Recession and in the subsequent period of declining growth rates were different. This may partly reflect the fact that the causes of the economic crisis in 2009 were different in nature from those underlying the 2015 recession. Our findings that there are different sets of best-performing indicators in the two sub-periods provide further confirmation of what many researchers have noted: a structural change in the underlying dynamics of economic growth and a marked fall in potential growth rates after the Global Financial Crisis (see e.g. Rautava, 2013).

Furthermore, the swings in economic growth in 2008-2010 have often been associated with changes in oil prices and with oil price-induced changes in foreign exchange rates. Contrary to the assumptions of many Russia-watchers, these two variables are in fact not especially accurate predictors of GDP growth. The Urals crude oil price makes it into the top ten only for the nowcast horizon of the 2012-2016 forecast period. The rouble foreign exchange rates never make 
a particularly good forecast. ${ }^{8}$ Several further indicators which are typically followed by analysts of the Russian business cycle do not figure in the top ten either (e.g. retail trade turnover, inflation and interest rates).

\subsection{Nowcast performance of top indicators over time}

In the following section, we show how the nowcast performance of selected top indicators evolves over time. Figure 1 depicts the actual quarterly GDP growth series from 2008-2016 (blue line), together with the pooled first monthly horizon GDP growth forecasts using money supply M0 (cash) in year-on-year growth rates as the indicator (brown line). This choice is motivated by the fact that money supply M0 turned out to be the best single indicator for the nowcast horizon in the forecast period 2012-2016 (see Section 5.1). In addition, the figure shows the $90 \%$ forecast or prediction interval (blue dotted lines). As can be seen from the figure, the single monthly indicator money supply M0 is extremely effective at nowcasting GDP growth, especially since 2013.

Figure 2 repeats the exercise with the RTS stock market index in yearon-year growth as the indicator instead of money supply M0. ${ }^{9}$ The US dollarbased stock market index was the third best single indicator for the nowcast horizon in the 2012-2016 forecast period and it was also clearly the best single indicator for the one-quarter-ahead forecast horizon in the same forecast period. For practitioners, the potential advantage of this particular indicator is that the publications are available in almost real time. Forecasts based on the stock market index are also relatively precise, but clearly overestimate the magnitude of the sudden slump in 2009Q1.

\subsection{Forecast accuracy of different model classes}

In the next step of our empirical analysis, we compare the performance of different model classes for nowcasting and short-term forecasting Russian GDP growth. Our aim is to ascertain whether the MIDAS and U-MIDAS approaches really do deliver higher forecast accuracy than the classical bridge equations approach.

In order to compare the model classes on the basis of the full set of 247 indicators, we build pooled forecasts over all indicators, but separately for each model class and each monthly horizon, as described in Section 4. This procedure ensures that our results are driven neither by differential availability of information

\footnotetext{
${ }^{8}$ The findings that the oil price and the rouble foreign exchange rate are less accurate predictors of GDP growth compared to other indicators do not imply any claims about causality. In particular, our findings are not in contradiction with the claim that Russian GDP is, to some extent, causally driven by oil shocks (and exchange rate shocks). Questions of causality are not studied in this paper.

${ }^{9}$ Figures for other indicators and other monthly forecast horizons are available on request.
} 
Figure 1. Nowcast of quarterly Russian GDP growth using money supply $\mathrm{MO}$ as a predictive indicator

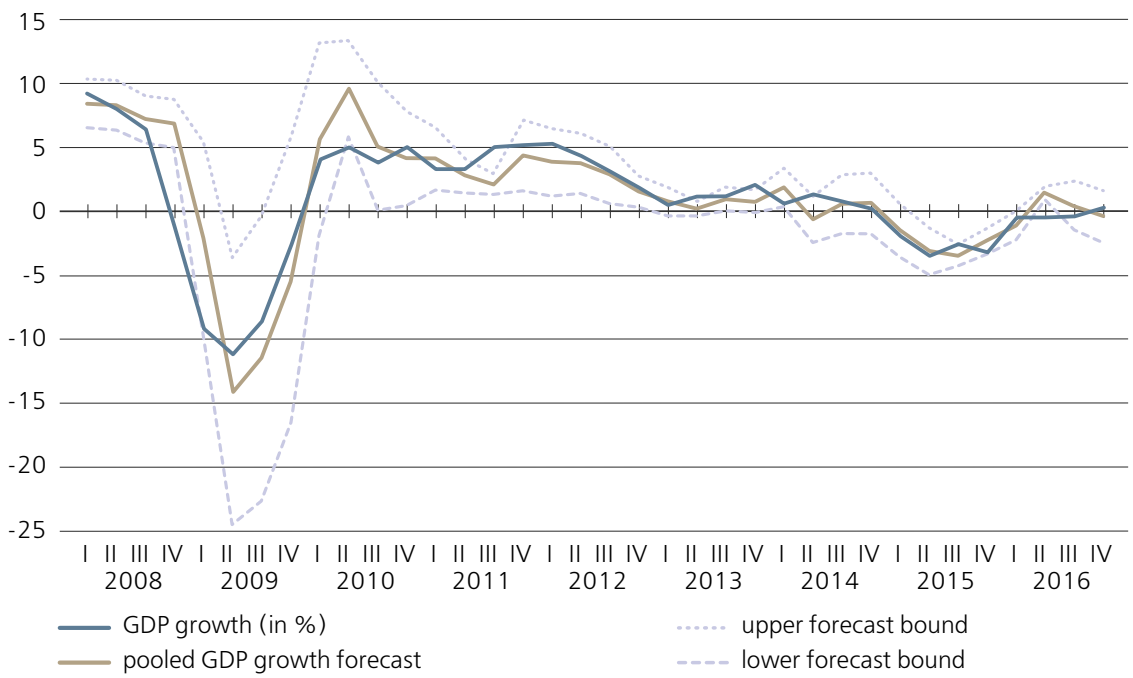

Note: the figure shows realised quarterly Russian GDP growth (blue line) over the period 2008Q1-2016Q4, together with the pooled first monthly horizon GDP growth forecasts using money supply M0 (cash) in yearon-year growth rates as the indicator (brown line). The figure also shows the $90 \%$ forecast or prediction interval (blue dotted lines). 'First monthly forecast horizon' means that GDP growth in quarter $t$ is forecasted at the end of the last month of $t$ (see Section 4). As quarterly Russian GDP growth is released around 1.5 months after the end of a quarter, the first monthly forecast horizon is still 1.5 months ahead of the GDP release for the quarter. The pooled single indicator forecast for each quarter within 2008Q1-2016Q4 is constructed in two steps (see Section 4). First, all first monthly horizon forecasts using money supply as the indicator stemming from all alternative model class specifications are pooled for each model class (bridge, MIDAS and U-MIDAS) separately. Second, the three (pooled) forecasts stemming from the three model classes are pooled again to one forecast (see Section 4 for a description of the pooling procedure).

Figure 2. Nowcast of quarterly Russian GDP growth using the RTS stock market index as a predictive indicator

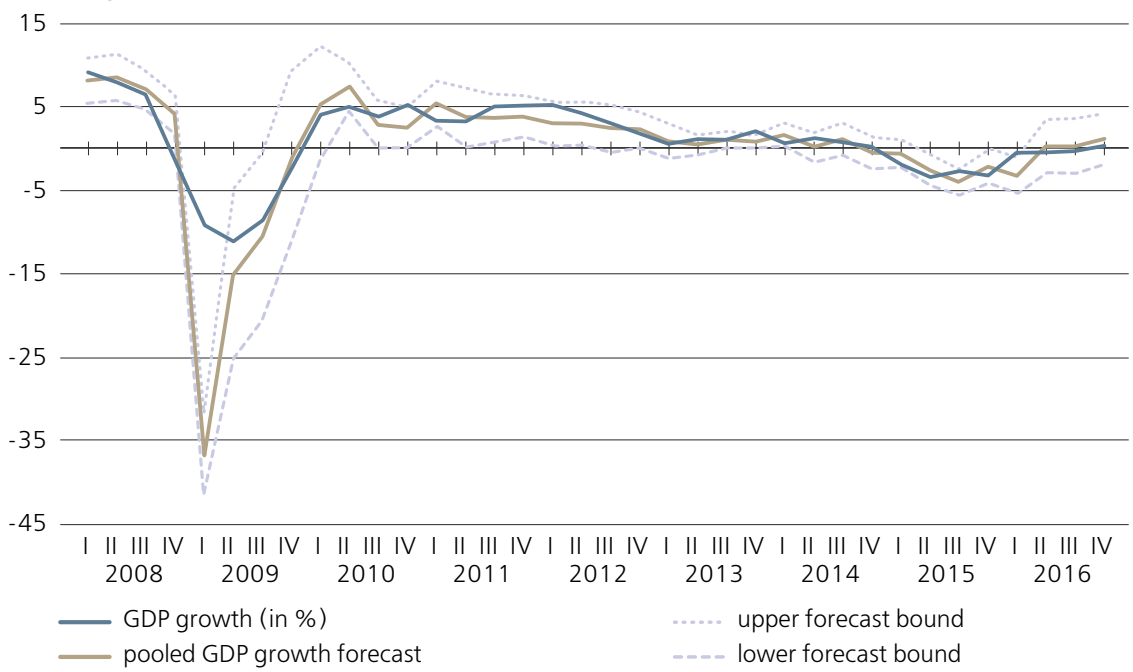

Note: see Figure 1. 
(each model class gets the same set of indicators) nor by a specific behaviour of a single indicator. Table 2 reports, for each of the two evaluation periods, the RMSFEs of the alternative model classes relative to the RMSFE of the benchmark forecast model (rolling window in-sample mean GDP growth). Again, values smaller than 1 indicate performance better than the benchmark.

Table 2. Performance of alternative forecast model classes in predicting quarterly Russian GDP growth

\begin{tabular}{|c|c|c|c|c|c|}
\hline & & \multirow{2}{*}{\multicolumn{2}{|c|}{ 2008-2011 }} & & \\
\hline & & & & \multicolumn{2}{|c|}{ 2012-2016 } \\
\hline & & $\begin{array}{l}\text { Nowcast } \\
\text { horizon }\end{array}$ & $\begin{array}{l}\text { One-quarter- } \\
\text { ahead forecast } \\
\text { horizon }\end{array}$ & $\begin{array}{l}\text { Nowcast } \\
\text { horizon }\end{array}$ & $\begin{array}{l}\text { One-quarter- } \\
\text { ahead forecast } \\
\text { horizon }\end{array}$ \\
\hline \multirow{2}{*}{ MIDAS model class } & $\begin{array}{l}\text { Relative } \\
\text { RMSFE }\end{array}$ & 0.54 & 0.89 & 0.33 & 0.49 \\
\hline & $p$-value & 0.01 & 0.01 & 0.00 & 0.00 \\
\hline \multirow{2}{*}{ U-MIDAS model class } & $\begin{array}{l}\text { Relative } \\
\text { RMSFE }\end{array}$ & 0.55 & 0.89 & 0.32 & 0.49 \\
\hline & $p$-value & 0.00 & 0.01 & 0.00 & 0.00 \\
\hline \multirow{2}{*}{ Bridge model class } & $\begin{array}{l}\text { Relative } \\
\text { RMSFE }\end{array}$ & 0.57 & 1.26 & 0.32 & 0.43 \\
\hline & $p$-value & 0.01 & 0.29 & 0.00 & 0.00 \\
\hline \multirow{2}{*}{$\begin{array}{l}\text { All model classes } \\
\text { (MIDAS, U-MIDAS, } \\
\text { bridge) }\end{array}$} & $\begin{array}{l}\text { Relative } \\
\text { RMSFE }\end{array}$ & 0.49 & 0.90 & 0.32 & 0.47 \\
\hline & $p$-value & 0.01 & 0.02 & 0.00 & 0.00 \\
\hline $\begin{array}{l}\text { Autoregressive } \\
\text { model class }\end{array}$ & $\begin{array}{l}\text { Relative } \\
\text { RMSFE }\end{array}$ & 0.61 & 1.05 & 0.43 & 0.64 \\
\hline
\end{tabular}

Note: see Table 1.

All model classes clearly perform better relative to the benchmark in the forecast period 2012-2016 than in the period 2008-2011. In this sense, the Russian economy has become more predictable. Moreover, the absolute RMSFEs for the period 2012-2016 are lower compared to the absolute RMSFEs for the period 2008-2011. This finding is not too surprising given the high economic volatility of 2008-2011. ${ }^{10}$

Furthermore, in the first period, forecasts stemming from the MIDAS model class and forecasts from the U-MIDAS model class perform significantly better than the benchmark forecasts, and also better than the forecasts from the bridge model class. In the second period, the differences between the forecast model classes are very small. This indicates that, in relative terms, MIDAS forecast models and U-MIDAS forecast models perform better in periods of high economic volatility.

\footnotetext{
${ }^{10}$ Results tables with absolute RMSFEs instead of relative RMSFEs are available on request from the authors of this paper.
} 


\section{Conclusions}

Work on forecasting Russian GDP growth is surprisingly scarce (Rautava, 2013; Porshakov, 2016; and Dahlhaus et al.; 2017). This paper makes several contributions to this area of study. We employ a large set of indicators, several mixed-frequency forecasting models, different forecast and nowcast horizons, and a long evaluation period in order to discover which indicators and models are particularly useful for short-term forecasting and nowcasting quarterly Russian GDP growth.

We examined the forecast accuracy of several mixed-frequency forecasting models. The differences in forecast performance between bridge models, MIDAS models and U-MIDAS models are quite small, except for the highly volatile recession and recovery period of 2008-2011, where U-MIDAS models and MIDAS models do better than bridge models.

We found numerous indicators that significantly improve upon simple benchmark models. Of especially importance to regular Russia-watchers, we showed that several monetary, banking, and financial market variables have better nowcast performance than crude oil prices and exchange rates.

Further, we observed that the best-performing indicators are clearly different in the 2008-2011 period and the 2012-2016 period which includes the transition towards slower growth and the recession of 2015. In the 2008-2011 period the best indicators include traditional real sector variables, whereas in the 2012-2016 period the best indicators are mostly monetary, banking sector and financial market variables. This finding supports the notion that highly volatile periods of recession and subsequent recovery are driven by forces different from those at play in more ordinary times. The results also support the argument that the driving forces of the Russian economy have changed in the wake of the global financial crisis.

The main purpose of this paper has been to ascertain which indicators have been most valuable for nowcasting and forecasting Russian GDP growth in recent years. For future research on forecasting the Russian economy, it would be worthwhile to focus more on the relative performance of different model classes. To the best of our knowledge, no comparison of a wide range of different mixed-frequency forecasting models such as bridge equations, MIDAS models, U-MIDAS models, dynamic factor models, large Bayesian VAR models, and machine learning approaches yet exists for Russia. It would also be interesting to study, in a unified framework, the accuracy of GDP forecasts for Russia compared to forecast accuracy for other countries. One of our findings has been that, in the 2012-2016 period, the best indicators are mostly monetary, banking sector and financial market variables. Elaborating on this finding, a comparison of the predictive power of different types of variables (e.g. real variables, monetary variables, survey data and financial 
data) across several countries, including Russia, would be another interesting topic for further research. ${ }^{11}$

Appendix is available at

http://www.cbr.ru/eng/money-and-finance;

dx.doi.org/10.31477/rjmf.201901.19

\section{References}

Almon, S. (1965). The Distributed Lag between Capital Appropriations and Expenditures. Econometrica, 33(1), pp. 178-196.

Andreou, E., Ghysels, E. and Kourtellos, A. (2010). Regression Models with Mixed Sampling Frequencies. Journal of Econometrics, 158(2), pp. 246-261.

Andreou, E., Ghysels, E. and Kourtellos, A. (2011). Forecasting with Mixed-Frequency Data. In: M.P. Clements and D.F. Hendry, eds. Oxford Handbook on Economic Forecasting, Oxford: Oxford University Press, pp. 225-245.

Andreou, E., Ghysels, E. and Kourtellos, A. (2013). Should Macroeconomic Forecasters Use Daily Financial Data and How? Journal of Business and Economic Statistics, 31(2), pp. 240-251.

Angelini, E., Camba-Méndez, G., Giannone, D., Rünstler, G. and Reichlin, L. (2011). Short-Term Forecasts of Euro Area GDP Growth. Econometrics Journal, 14(1), pp. C25-C44.

Armesto, M. T., Engemann, K. M. and Owyang, M. T. (2010). Forecasting with Mixed Frequencies. Federal Reserve Bank of St. Louis Review, 92(6), pp. 521-536.

Baffigi, A., Golinelli, R. and Parigi, G. (2004). Bridge Models to Forecast the Euro Area GDP. International Journal of Forecasting, 20(3), pp. 447-460.

Baker, S. R., Bloom, N. and Davis S. J. (2015). Measuring Economic Policy Uncertainty. NBER Working Papers, N 21633.

Blinov, S. (2017). Economic Forecasting Based on the Relationship between GDP and Real Money Supply. MPRA Paper, N 78717.

Bulligan, G., Golinelli, R. and Parigi, G. (2010). Forecasting Monthly Industrial Production in Real-Time: From Single Equations to Factor-Based Models. Empirical Economics, 39(2), pp. 303-336.

Bulligan, G., Marcellino, M. and Venditti, F. (2015). Forecasting Economic Activity with Targeted Predictors. International Journal of Forecasting, 31(1), pp. 188-206.

Camacho, M., Perez-Quiros, G. and Poncela, P. (2013). Short-Term Forecasting for Empirical Economists. A Survey of the Recently Proposed Algorithms. Foundations and Trends in Econometrics, 6(2), pp. 101-161.

Chow, G. C. and Lin, A.-L. (1971). Best Linear Unbiased Interpolation, Distribution, and Extrapolation of Time Series by Related Series. The Review of Economics and Statistics, pp. 372-375.

\footnotetext{
${ }^{11}$ We are grateful to three anonymous referees for these suggestions for further research.
} 
Clements, M. P. and Galvão, A. B. (2008). Macroeconomic Forecasting with MixedFrequency Data. Journal of Business and Economic Statistics, 26(4), pp. 546-554.

Clements, M. P. and Galvão, A. B. (2009). Forecasting US Output Growth Using Leading Indicators: An Appraisal Using MIDAS Models. Journal of Applied Econometrics, 24(7), pp. 1187-1206.

Dahlhaus, T., Guénette, J. D. and Vasishtha, G. (2017). Nowcasting BRIC+M in Real Time. International Journal of Forecasting, 33(4), pp. 915-935.

Diron, M. (2008). Short-Term Forecasts of Euro Area Real GDP Growth: An Assessment of Real-Time Performance Based on Vintage Data. Journal of Forecasting, 27(5), pp. 371-390.

Drechsel, K. and Scheufele, R. (2012). The Performance of Short-Term Forecasts of the German Economy Before and During the 2008/2009 Recession. International Journal of Forecasting, 28(2), pp. 428-445.

Duarte, C. (2014). Autoregressive Augmentation of MIDAS Regressions. Banco de Portugal Working Papers, N 1.

Ferrara, L., Marsilli, C. and Ortega, J.-P. (2014). Forecasting Growth during the Great Recession: Is Financial Volatility the Missing Ingredient? Economic Modelling, 36, pp. 44-50.

Foroni, C. and Marcellino, M. (2013). A Survey of Econometric Methods for MixedFrequency Data. Norges Bank Working Papers, N 6.

Foroni, C. and Marcellino, M. (2014). A Comparison of Mixed Frequency Approaches for Nowcasting Euro Area Macroeconomic Aggregates. International Journal of Forecasting, 30(3), pp. 554-568.

Foroni, C., Marcellino, M. and Schumacher, C. (2015). Unrestricted Mixed Data Sampling (MIDAS): MIDAS Regressions with Unrestricted Lag Polynomials. Journal of the Royal Statistical Society, Series A, 178(1), pp. 57-82.

Ghysels, E., Sinko, A. and Valkanov, R. (2007). MIDAS Regressions: Further Results and New Directions. Econometric Reviews, 26(1), pp. 53-90.

Giacomini, R. and White, H. (2006). Tests on Conditional Predictive Ability. Econometrica, 74(6), pp. 1545-1578.

Giannone, D., Reichlin, L. and Small, D. (2008). Nowcasting: The Real-Time Informational Content of Macroeconomic Data. Journal of Monetary Economics, 55(4), pp. 665-676.

Golinelli, R. and Parigi, G. (2007). The Use of Monthly Indicators to Forecast Quarterly GDP in the Short Run: An Application to the G7 Countries. Journal of Forecasting, 26(2), pp. 77-94.

Hahn, E. and Skudelny, F. (2008). Early Estimates of Euro Area Real GDP Growth: A Bottom-up Approach from the Production Side. ECB Working Papers, N 975.

Ingenito, R. and Trehan, B. (1996). Using Monthly Data to Predict Quarterly Output. Federal Reserve Bank of San Francisco Economic Review, 3, pp. 3-11.

Kuzin, V., Marcellino, M. and Schumacher, C. (2013). Pooling Versus Model Selection for Nowcasting GDP with Many Predictors: Empirical Evidence for Six Industrialized Countries. Journal of Applied Econometrics, 28(3), pp. 392-411. 
Mikosch, H. and Solanko, L. (2017). Should One Follow Movements in the Oil Price or in Money Supply? Forecasting Quarterly GDP Growth in Russia with HigherFrequency Indicators. BOFIT Discussion Papers, N 19.

Mikosch, H. and Zhang, Y. (2014). Forecasting Chinese GDP Growth with Mixed Frequency Data: Which Indicators to Look at? KOF Working Paper, N 359.

Porshakov, A., Ponomarenko, A. and Sinyakov, A. (2016). Nowcasting and Short-Term Forecasting of Russian GDP with a Dynamic Factor Model. Journal of New Economic Association, 2(30), pp. 60-76. [In Russian].

Rautava, J. (2013). Oil Prices, Excess Uncertainty and Trend Growth. A Forecasting Model for Russia's Economy. Focus on European Economic Integration, 4, pp. 77-87.

Rünstler, G., Barhoumi, K., Benk, S., Cristadoro, R., Den Reijer, A., Jakaitiene, A., Jelonek, P., Rua, A., Ruth, K. and Van Nieuwenhuyze, C. (2009).

Short-Term Forecasting of GDP Using Large Datasets: A Pseudo Real-Time Forecast Evaluation Exercise. Journal of Forecasting, 28(7), pp. 595-611.

Schumacher, C. (2016). A Comparison of MIDAS and Bridge Equations. International Journal of Forecasting, 32(2), pp. 257-270.

Stock, J. H. and Watson, M. W. (2004). Combination Forecasts of Output Growth in a Seven-Country Data Set. Journal of Forecasting, 23(6), pp. 405-430.

Timmermann, A. (2006). Forecast Combinations. In: E. Graham, C. Granger and A. Timmermann, eds. Handbook of Economic Forecasting, Vol. 1, pp. 136-196.

Wallis, K. F. (1986). Forecasting with an Econometric Model: The 'Ragged Edge' Problem. Journal of Forecasting, 5(1), pp. 1-13. 